\title{
Participation of Endogenous Dehydroepiandrosterone and Its Sulfate in the Pathology of Collagen-Induced Arthritis in Mice
}

\author{
Yoshiharu Kobayashi, ${ }^{*},{ }^{, a}$ Noriko Tagawa, ${ }^{a}$ Kimie Muraoka, ${ }^{a}$ Yoshihiro Okamoto, ${ }^{b}$ and \\ Mikio NiSHIDA ${ }^{b}$ \\ ${ }^{a}$ Clinical Chemistry Laboratory, Kobe Pharmaceutical University; 4-19-1 Motoyamakita-machi, Higashinada-ku, Kobe \\ 658-8558, Japan: and ${ }^{b}$ Department of Clinical Pharmacy, Faculty of Pharmacy, Meijo University; Nagoya 466-8650, \\ Japan. Received June 9, 2003; accepted August 22, 2003
}

We have investigated the serum levels of dehydroepiandrosterone (DHEA) and DHEA sulfate (DHEAS) in type II collagen (CII)-induced arthritis (CIA) DBA/1J mice, an experimental model of human rheumatoid arthritis (RA). Serum levels of DHEA and DHEAS were measured by EIA and GC/MS, respectively. Sera were obtained from the mice on day $6,13,28$ and 48 after the CII treatment. The disease onset of CIA was observed from day $28(7 \%)$ to day $48(80 \%)$ after CII immunization. The serum concentration of DHEA on day 13 did not differ from that on day 6 in CIA mice and untreated controls. Serum levels of DHEA on day 28 and 48 were significantly low compared with those on day 6 in controls. However, in CIA mice, DHEA levels on day 28 and 48 were not decreased from those on day 6 . No difference in the serum DHEAS level on day 13 compared with day 6 was observed in either control or CIA mice. A significant decrease of DHEAS levels on day 28 and 48 compared with day 6 was found in both groups. The time point for the retention of DHEA in CIA mice, day 28 and day 48 , coincided with the disease onset of CIA. In conclusion, endogenous DHEA may be produced as a result of physiological response for the protection against CIA.

Key words dehydroepiandrosterone; rheumatoid arthritis; collagen-induced arthritis

Type II collagen-induced arthritis (CIA) in animals is an experimental model of the human autoimmune disease, rheumatoid arthritis (RA) and is characterized by a severe swelling of the paws associated with a massive infiltration of inflammatory cells into the joints. Induction of the disease is usually initiated by an injection of type II collagen emulsified in complete Freund's adjuvant into genetically susceptible DBA/1J mice. ${ }^{1,2)}$ Both B and T lymphocytes, particularly of $\mathrm{CD}^{+} \mathrm{T}$ cells, are required for the induction of this experimental disease. ${ }^{3-5)}$ Murine $\mathrm{CD} 4^{+} \mathrm{T}$ helper (Th) cell clones can be subdivided into at least two distinct functional subsets based on their cytokine excretion profiles. $\left.{ }^{6}\right)$ The first type of clone (Th1) produces interleukin-2 (IL-2) and interferon- $\gamma$ (IFN- $\gamma$ ) but not IL-4 or IL-6. The second type (Th2) produces IL- 4 and IL- 6 but not IL-2 or IFN- $\gamma$. CIA has been classified as a Th1-mediated disease. Most of the evidence for this has been indirect; for example, the administration of neutralizing anti-IFN- $\gamma$ antibody reduced the severity of arthritis. $^{7)}$

Dehydroepiandrosterone (DHEA) and its sulfate ester (DHEAS) are the most abundant circulating steroids in humans. However, the physiological role of these steroids has long been unknown. Recently, it was clarified that androgen and estrogen are mainly produced by peripheral tissues from the adrenal precursor DHEA and DHEAS. ${ }^{8,9)}$ Moreover, it has been suggested that these steroids have some protective effect against cardiovascular disease, obesity, hypercholesterolemia, cancer, Alzheimer's disease, insulin-dependent diabetes mellitus and other immune modulated diseases. ${ }^{10-14)}$ Furthermore, serum DHEA and DHEAS levels have been reported to be decreased in premenopausal women with RA compared with age-matched controls. ${ }^{15,16)}$

DHEA enhances the production of IL-2 by murine and human activated $\mathrm{T}$ cells, and reverses the suppression of blastogenic responses and IL-2 production initiated by corticosteroids. ${ }^{17-19)}$ On the other hand, DHEAS decreases the expression and activity levels of the IL-6 gene promoter, ${ }^{20)}$ and IL-6 expression has been found to be inversely correlated with serum DHEAS levels both in RA patients and in healthy subjects. ${ }^{16,21)}$

This paper describes an involvement of DHEA not DHEAS in the pathology of CIA.

\section{MATERIALS AND METHODS}

Animals Male DBA/1J mice (8-week-old) were obtained from Charles River Japan (Kanagawa, Japan). After a resting period of 1 week, these animals were subjected to the experimental protocols.

Induction of Arthritis Arthritis was induced by the injection of bovine type II collagen (CII) (Elastin Products Co., MO, U.S.A.) according to a method described by Courtenay et $a l^{2)}$ Male DBA/ $1 \mathrm{~J}$ mice (9 weeks old) were injected intradermally in the right foodpad with $200 \mu \mathrm{g}$ of bovine CII emulsified in Freund's complete adjuvant (FCA). On day 13 after the first treatment, the animals were boosted with an intraperitoneal (i.p.) injection of $200 \mu \mathrm{g}$ of CII dissolved in phosphate-buffered saline (PBS).

Extraction and Assay Procedure for Serum DHEA and DHEAS Full details of the sample extraction, enzyme immunoassay (EIA) for DHEA (Sigma, Milwaukee) and GC/MS measurement of DHEAS (Sigma) have been described elsewhere. ${ }^{22,23)}$ In short, blood from DBA/1J mice was obtained by decapitation. The separation of DHEA and DHEAS from serum samples was carried out using $0.2 \mathrm{ml}$ of serum sample. The serum sample was extracted with $1 \mathrm{ml}$ of methanol. The extract was subjected to solid phase extraction using a reversed-phase column, Sep-Pak Vac tC1 $8^{\circledR}$ (Waters Corporation, Milford, MA, U.S.A.) and an anion exchange column, Accell Plus QMA ${ }^{\circledR}$ (Waters). With these treatments, the steroid glucuronides were excluded and the unconjugated fraction (DHEA) and the mono-sulfate fraction (DHEAS) 
were obtained.

The unconjugated fraction was subjected to HPLC: mobile phase, water-acetonitorile $(70: 30, \mathrm{v} / \mathrm{v})$; column: Wakosil-II 5C18-HG $150 \mathrm{~mm} \times 4.6 \mathrm{~mm}$ i.d. (Wako Pure Chemical Industries, Osaka Japan); flow rate: $1 \mathrm{ml} / \mathrm{min}$. The eluate from between 15.2 and 17.7 min was collected as the DHEA fraction. The solvent was evaporated under vacuum and the residue was dissolved in $0.25 \mathrm{ml}$ of methanol. Aliquots of $0.1 \mathrm{ml}$ of this solution were transferred into two tubes. After evaporation of the solution, $0.5 \mathrm{ml}$ of rabbit anti-DHEA antiserum diluted with assay buffer ( $0.07 \mathrm{M}$ phosphate buffer $(\mathrm{pH} 7.4)$ containing $0.25 \%$ bovine serum albumin) and $0.1 \mathrm{ml}$ of alkaline phosphatase (ALP)-labeled DHEA containing $0.6 \%$ normal rabbit serum were added. The tubes were then stood at room temperature for $1 \mathrm{~h}, 0.1 \mathrm{ml}$ of $3 \%$ second antibody diluted with the assay buffer was added and the mixture was allowed to stand at $4{ }^{\circ} \mathrm{C}$ overnight. After $\mathrm{B} / \mathrm{F}$ separation by centrifugation, the enzyme activity of the resulting precipitate was measured using the kit Alkaline Phospha K-Test ${ }^{\circledR}$ (Wako Pure Chemical Industries). The coefficients of variation (C.V.) for the intra- and inter-assay were 5.6 and $8.9 \%$, respectively.

The mono-sulfate fraction was hydrolyzed with arylsulfatase (EC 3.1.6.1. from Helix pomatia, Boehringer Mannheim). The resulting samples were subjected to HPLC as for the DHEA assay. Androstenediol diacetate in methanol (40 $\mathrm{ng} /$ sample) was added to each sample as an internal standard for GC/MS. After evaporation, derivatization was performed with heptafluorobutyric anhydride (GL Sciences, Tokyo, Japan) at $60{ }^{\circ} \mathrm{C}$ for $30 \mathrm{~min}$. The reaction mixture was evaporated to dryness. The residue was dissolved in $0.4 \mathrm{ml}$ of dichloromethane and $2 \mu \mathrm{l}$ of the sample was analyzed by GC/MS. The C.V. for the intra- and inter-assays was 2.3 and $5.4 \%$, respectively.

Cell Preparation Spleen cells were prepared as described previously. ${ }^{24,25)}$ In brief, spleen cells from DBA/1J mice were aseptically removed, and a single cell suspension was prepared in RPMI 1640 medium supplemented with $10 \%$ fetal bovine serum.

Procedure for Cytokine Assay The concentration of IL2 or IL-4 in culture supernatants was determined by specific ELISA. $^{26)}$ Flat-bottomed microtiter plates were coated with anti-mouse IL-2 or IL-4 monoclonal antibody (mAb) and blocked with $300 \mu \mathrm{l}$ of phosphate buffered saline (PBS) containing $1 \% \mathrm{BSA}, 1 \%$ sucrose and $0.05 \%$ Tween 20 for $90 \mathrm{~min}$ at room temperature. The plates were then washed three times with phosphate buffered saline (PBS) containing $0.05 \%$ Tween 20 (PBS-T). Culture supernatant or recombinant (r) murine cytokines (R\&D systems Inc. MN, U.S.A.), which was used to construct the standard curve $(0-20$ $\mathrm{ng} / \mathrm{ml}$ ), was serially diluted with RPMI 1640 medium. One hundred microliter of the samples was incubated in the wells at $4{ }^{\circ} \mathrm{C}$ overnight. After the incubation, the plate was washed and biotinylated anti-murine IL-2 or IL-4 mAb (R\&D systems Inc., MN, U.S.A.) was added and incubated for $2 \mathrm{~h}$ at room temperature. The plates were washed and $100 \mu \mathrm{l}$ of horseradish peroxidase (HRP)-conjugated streptavidin was added. The plates were washed and $100 \mu \mathrm{l}$ of $0.05 \mathrm{M}$ citrate phosphate buffer, pH 5.8 containing $0.4 \mu \mathrm{g} / \mathrm{ml} o$-phenylendiamine (DAKO Japan, Kyoto, Japan) and 0.0013\% hydrogen peroxide, was added to each well. After $15 \mathrm{~min}$ the enzyme- substrate reaction was terminated by the addition of $100 \mu \mathrm{l}$ of $0.5 \mathrm{~m}$ sulfuric acid. The absorbance at $490 \mathrm{~nm}$ was measured in microplate reader Model 3550UV (Biorad Laboratories, CA, U.S.A.). Data reduction and calculation were carried out with analysis software package (Microplate Manager ver.2, BioRad). Detection limit of the assays for both cytokines was $0.08 \mathrm{ng} / \mathrm{ml}$. The intra- and inter-assay coefficients of variation were 3.9 and $3.3 \%$, respectively. Mean recovery from culture medium samples ranged from 89 to $97 \%$.

\section{RESULTS}

Incidence and Time of Onset of Arthritis in DBA/1J Mice The incidence and the day of onset of arthritis in mice injected with CII are shown in Fig. 1. Arthritis was observed from $33 \mathrm{~d}$ after the immunization. The onset of arthritis in the present experiment was consistent with previous studies. $^{25,27)}$

Serum Levels of DHEA and DHEAS during the Development of Arthritis in CIA Mice During the development of arthritis after the administration of CII to DBA/1 J mice, serum levels of DHEA and DHEAS were measured by EIA and GC/MS, respectively. Sera were obtained on day 6,13 , 28 and 48 after the first CII treatment. The serum concentration of DHEA on day 13 was not different from that on day 6 in CIA and untreated control mice, respectively. Serum levels of DHEA on day 28 and 48 were significantly low compared with those of day 6 in controls. However, DHEA levels on day 28 and 48 were not decreased from those on day 6 in CIA (Fig. 2).

No difference of serum DHEAS level on day 13 compared with day 6 was observed in control or CIA mice. Significant decrease in the level of DHEAS on day 28 and 48 compared with day 6 was found in control and CIA mice, respectively.

IL-2 and IL-4 Production by Spleen Cells At different times after the immunization with CII, a single cell suspension of spleen cells was prepared and the production of IL-2 and IL-4 was determined after the stimulation with CII or concanavalin A (Con A, Sigma) (Fig. 3). The production of IL-2, Th1 cytokine, from the CII-stimulated spleen cells increased on day 6. However, on day 13, 28 and 48, the production of IL-2 decreased to $40 \%$ of that on day 6 (Fig. $3 \mathrm{~A}$ ). The IL-2 excretion from spleen cells stimulated with Con A

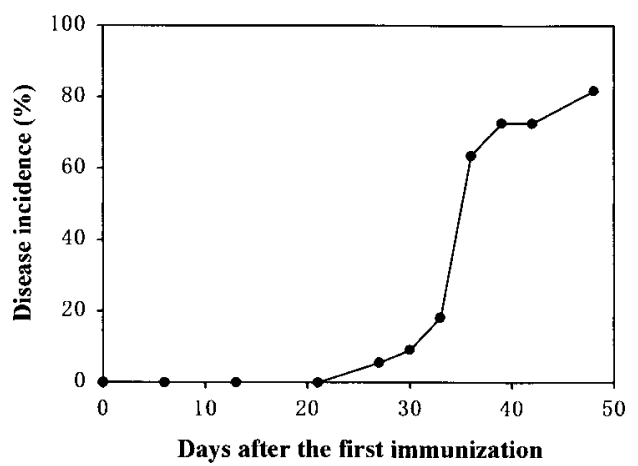

Fig. 1. Incidence and Onset of Arthritis in DBA/1J Mice

Male DBA/1J mice were injected intradermally in the right footpad with $200 \mu \mathrm{g}$ of bovine CII emulsified in FCA, followed on day 13 by an i.p. injection of $200 \mu \mathrm{g}$ of CII dissolved in PBS. The disease onset of CIA was estimated from the erythema and edema of paws other than the right foot. Results represent the percentage of mice with clinical arthritis in one or more joints $(n=6)$. 

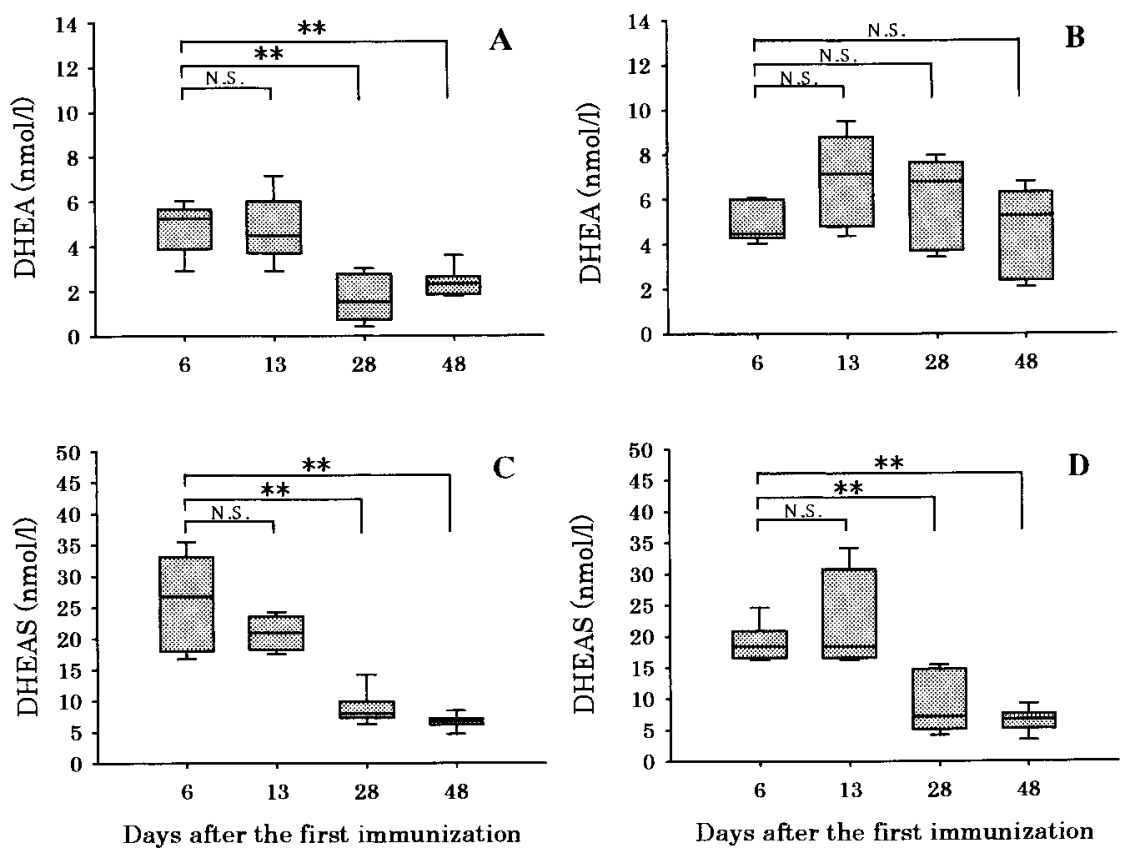

Fig. 2. Serum Levels of DHEA (A, B) and DHEAS (C, D) during Development of Arthritis in CIA Mice

A, C: control mice. Physiological saline $(0.9 \% \mathrm{NaCl})$ was injected instead of bovine CII; B, D: CIA mice. Mice were injected intradermally in the right footpad with $200 \mu \mathrm{g}$ of CII emulsified in FCA, followed on day 13 by an i.p. injection of $200 \mu \mathrm{g}$ of CII dissolved in PBS. A line within the box marks the median, and a box represents quartile deviation. Whiskers above and below the box indicate the 90th and 10th percentiles. $* * p<0.01$ vs. day 6 .

also decreased on day 13, 28 and 48 (Fig. 3B). On the other hand, the production of IL-4, Th2 cytokine, increased up to $320 \%$ compared to that from the Con A-stimulated spleen cells of control mice on day 28 and 48 (Fig. 3C).

\section{DISCUSSION}

DHEA and DHEAS were produced from pregnenolone (Preg) and pregnenolone sulfate (PregS) by cytochrome p450c17 (CYP17), respectively. This enzyme catalyzes two sequential reactions, the first being hydroxylation of the $\mathrm{C} 17$ of Preg or PregS. This reaction can be followed by cleavage of the $\mathrm{C} 17$ and $\mathrm{C} 20$ bond of 17-hydroxy-Preg (17-OH-Preg) or 17-OH-Preg sulfate (17-OH-PregS) with the resultant formation of DHEA or DHEAS. ${ }^{2829)}$ Although CYP17 is expressed in adrenals and gonads in humans, the enzyme is not expressed in rodent adrenals ${ }^{30)}$ but in liver. Thus DHEA(S) originates from liver or gonadal glands in mice or rats. Katagiri et al. reported that the expression of CYP17 in rat liver microsomes was reduced to undetectable levels in 7- and 14week old rats based on an immunoblot analysis. ${ }^{31)}$ In the present study, DHEA levels were significantly decreased on day 28 (13 week old) and day 48 (16 week old) in control mice (Fig. 2A). This may be partly due to the decrease in the expression of CYP17 in mice liver as in rat liver. In CIA mice, however, no such decreases were observed (Fig. 2B). At present, the mechanisms behind the retention of DHEA in CIA mice on day 28 and day 48 are unknown. It is worth keeping in mind that these time points coincided with the disease onset of CIA (Fig. 1). In our previous report, we showed that most CII-specific $\mathrm{CD}^{+}{ }^{+} \mathrm{T}$ cells which develop at the prearthritic phase are Th1 cells, and after the onset of arthritis, the generation of Th2 cells is stimulated. ${ }^{25)}$ These changes in the Th balance during the course of CIA development have also been reported by others. ${ }^{32)}$ Much evidence for
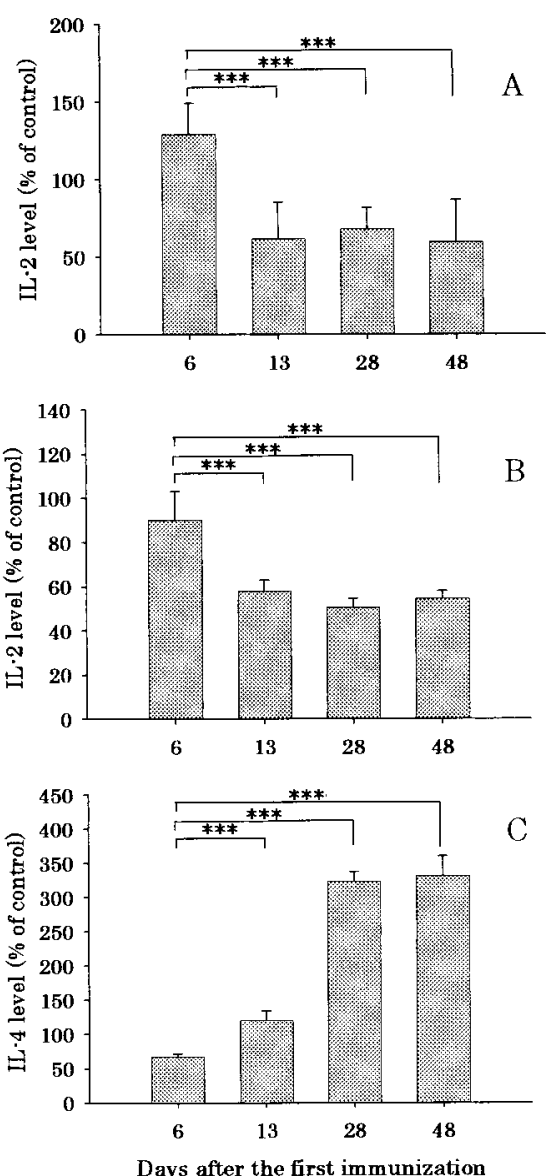

Fig. 3. IL-2 (A, B) and IL-4 (C) Production from Activated Spleen Cells

Spleen cells from DBA/1J mice were aseptically removed, and the cell suspension was prepared in RPMI 1640 medium supplemented with $10 \%$ fetal bovine serum. IL-2 and IL-4 levels in the culture medium were measured by ELISA after $48 \mathrm{~h}$ stimulation with CII (A) and Con A (B, C) $(n=3)$. Cytokine levels $(n=3)$ were expressed as percentage of controls $(0.9 \% \mathrm{NaCl}$ treatment $) . * * * p<0.001 v s$. day 6 . 
inducible roles of Th1-type cytokines, IL- 2 and IFN- $\gamma$, in CIA development has been reported. ${ }^{32-35)}$ Conversely, Th2type cytokines, IL-4 and IL-10, have been reported to ameliorate CIA. ${ }^{36-40)}$ Thus the activation of Th2 cells may contribute to the remission phase of CIA. ${ }^{41)}$ In the present study, the levels of the Th2 cytokine, IL-4, was significantly increased on day 28 and day 48 in CIA mice (Fig. 3C).

It has been reported that postmenopausal RA patients had significantly reduced levels of DHEA and DHEAS compared with normal postmenopausal women. ${ }^{15,16)}$ Moreover, Williams et al. reported that administration of exogenous DHEA to DBA/1J CIA mice prevented the development of CIA. ${ }^{42)}$ Taking these findings into account, the retention of DHEA on day 28 and day 48 in CIA mice may be the result of the physiological response in protection against CIA.

\section{REFERENCES}

1) Trentham D. E., Townes A. S., Kang A. H., J. Exp. Med., 146, 857868 (1977).

2) Courtenay J. S., Dallman M. J., Dayan A. D., Martin A., Mosedale B., Nature (London), 283, 666-668 (1980).

3) Ranges G. E., Sriram S., Cooper S. M., J. Exp. Med., 162, 1105-1110 (1985).

4) Watson W. C., Townes A. S., J. Exp. Med., 162, 1878-1891 (1985).

5) Kakimoto K., Katsuki M., Hirofuji T., Iwata H., Koga T., J. Immunol., 140, 78-83 (1988).

6) Mosmann T. R., Cherwinski H., Bond M. W., Giedlin M. A., Coffman R. L., J. Immunol., 136, 2348-2357 (1986).

7) Boissier M. C., Chiocchia G., Bessis N., Hajnal J., Garotta G., Nicoletti F., Fournier C., Eur. J. Immunol., 25, 1184-1190 (1995).

8) Labrie F., Belanger A., Simard J., Van L. T., Labrie C., Ann. N.Y. Acad. Sci., 774, 16-28 (1995).

9) Kroboth P. D., Salek F. S., Pittenger A. L., Fabian T. J., Frye R. F., J. Clin. Pharmacol., 39, 327-348 (1999).

10) Barrett-Connor E., Khaw K. T., Yen S. S., N. Engl. J. Med., 315, 1519-1524 (1986).

11) Gordon G. B., Bush D. E., Weisman H. F., J. Clin. Invest., 82, 712720 (1988).

12) Schwartz A. G., Perantoni A., Cancer Res., 35, 2482-2487 (1975).

13) Mohan P. F., Lancet, 2, 1048-1049 (1989).

14) Daynes R. A., Araneo B. A., Dowell T. A., Huang K., Dudley D., J. Exp. Med., 171, 979-996 (1990).

15) Sambrook P. N., Eisman J. A., Champion G. D., Pocock N. A., Arthritis Rheum., 31, 973-978 (1988).

16) Cutolo M., Foppiani L., Prete C., Ballarino P., Sulli A., Villaggio B., Seriolo B., Giusti M., Accardo S., J. Rheumatol., 26, 282-288 (1999).

17) Daynes R. A., Dudley D. J., Araneo B. A., Eur. J. Immunol., 20, $793-$ 802 (1990).
18) Suzuki T., Suzuki N., Daynes R. A., Engleman E. G., Clin. Immmol. Immunopathol., 61, 202-211 (1991).

19) Blauer K. L., Poth M., Rogers W. M., Bernton E. W., Endocrinol., 129, 3174-3179 (1991).

20) Bellido T., Jilka R. L., Boyce B. F., Girasole G., Broxmeyer H., Dalrymple S. A., Murray R., Manolagas S. C., J. Clin. Invest., 95, 28862895 (1995).

21) Straub R. H., Konecna L., Hrach S., Rothe G., Kreutz M., Scholmerich J., Falk W., Lang B., J. Clin. Endocrinol. Metab., 83, 2012-2017 (1998).

22) Tagawa N., Nakata Y., Kusuda S., Kobayashi Y., Watanabe F., Biol. Pharm. Bull., 20, 76-78 (1997).

23) Tagawa N., Tamanaka J., Fujinami A., Kobayashi Y., Takano T., Fukata S., Kuma K., Tada H., Amino N., Clin. Chem., 46, 523-528 (2000).

24) Okamoto Y., Murakami H., Nishida M., Endocr. J., 44, 349-355 (1997).

25) Okamoto Y., Gotoh Y., Tokui H., Mizuno A., Kobayashi Y., Nishida M., J. Interferon Cytokine Res., 20, 55-61 (2000).

26) Okamoto Y., Nagai T., Abe T., Ishikawa S., Ishizuka H., Nishida M., Biomed. Res., 9, 179-185 (1998).

27) Cortenay J. S., Dallman, M. J., Dayan, A. D., Martin, A., Mosedale, B., Nature (London), 283, 666-668 (1980).

28) Nakajin S., Hall P. F., J. Biol. Chem., 256, 3871-3876 (1981).

29) Kagimoto M., Winter J. S. D., Kagimoto K., Simpson E. R., Waterman M. R., Mol. Endocrinol., 2, 564-570 (1988).

30) van Weerden W. M., Bierings H. G., van Steenbrugge G. J., de Jong F. H., Schroder F. H., Life Sci., 50, 857-861 (1992).

31) Katagiri M., Tatsuta K., Imaoka S., Funae Y., Honma K., Matsuo N., Yokoi H., Ishimura K., Ishibashi F., Kagawa N., J. Steroid Biochem. Mol. Biol., 64, 121-128 (1998).

32) Doncarli A., Stasiuk L. M., Fournier C., Abehsira-Amar O., Eur. J. Immunol., 27, 1451-1458 (1997).

33) Boissier M.-C., Chiocchia G., Bessis N., Hajnal J., Garotta G., Nicoletti F., Fournier C., Eur. J. Immunol., 25, 1184-1190 (1995).

34) Mauritz J. N., Holmdahl R., Jonsson R., Van der Meide H. P., Scheynius A., Klareskog L., Arthritis Rheum., 31, 1297-1304 (1988).

35) Nakajima H., Takamori H., Hiyama Y., Tsukada W., Clin. Exp. Immunol., 81, 441—445 (1990).

36) Bessis N., Boissier M., Ferrara P., Blankenstein T., Fradelizi D., Fournier C., Eur. J. Immunol., 26, 2399-2403 (1996).

37) Yoshino S., Br. J. Pharmcol., 123, 237-242 (1998).

38) Marcelletti J. F., Ohara J., Katz D. H., J. Immunol., 147, 4185-4191 (1991).

39) Ma Y., Thornton S., Duwel L. E., Boivin G. P., Giannini E. H., Leiden J. M., Bluestone J. A., Hirsch R., J. Immunol., 161, 1516-1524 (1998).

40) Joosten L. A. B., Lubberts E., Durez P., Helsen M., Jacobs M., Goldman M., van Den Berg W. B., Arthritis Rheum., 40, 249-260 (1997).

41) Mauri C., Williams R. O., Walmsley M., Feldmann M., Eur. J. Immunol., 26, 1511-1518 (1996).

42) Williams P. J., Jones R. H., Rademacher T. W., Arthritis Rheum., 40, 907-911 (1997). 